\title{
International palliative care experts' view on phenomena indicating the last hours and days of life
}

\author{
Franzisca Domeisen Benedetti - Christoph Ostgathe • Jean Clark • \\ Massimo Costantini • Maria Laura Daud • Barbara Grossenbacher-Gschwend • \\ Richard Latten • Olav Lindqvist • Andreja Peternelj • Stefanie Schuler • Kali Tal • \\ Agnes van der Heide $\cdot$ Steffen Eychmüller $•$ on behalf of OPCARE9
}

Received: 16 October 2012 / Accepted: 26 November 2012 /Published online: 15 December 2012

(C) Springer-Verlag Berlin Heidelberg 2012

\begin{abstract}
Background Providing the highest quality care for dying patients should be a core clinical proficiency and an integral part of comprehensive management, as fundamental as diagnosis and treatment. The aim of this study was to provide expert consensus on phenomena for identification and prediction of the last hours or days of a patient's life. This study
\end{abstract}

F. Domeisen Benedetti $(\bowtie) \cdot$ B. Grossenbacher-Gschwend

S. Schuler

Centre of Palliative Care, Cantonal Hospital of St.Gallen,

Rorschacherstrasse 95,

9007 St. Gallen, Switzerland

e-mail: franzisca.domeisen@kssg.ch

C. Ostgathe

Division of Palliative Medicine, University of Erlangen,

Erlangen, Germany

J. Clark

Education and Research Unit, Arohanui Hospice,

Palmerston North, New Zealand

\section{Costantini}

Regional Palliative Care Network,

IRCCS AOU San Martino-IST, Genoa, Italy

\section{L. Daud}

Pallium Latinoamerica NGO,

Buenos Aires, Argentina

\section{R. Latten}

Marie Curie Palliative Care Institute,

University of Liverpool, Liverpool, UK

\section{O. Lindqvist}

$\mathrm{R} \& \mathrm{D}$ unit in palliative care,

Stockholms Sjukhem Foundation, Stockholm, Sweden is part of the OPCARE9 project, funded by the European Commission's Seventh Framework Programme.

Method The phenomena associated with approaching death were generated using Delphi technique. The Delphi process was set up in three cycles to collate a set of useful and relevant phenomena that identify and predict the last hours and days of life. Each cycle included: (1) development of

\section{O. Lindqvist}

Department of Learning, Informatics,

Management and Ethics, Karolinska Institutet,

Stockholm, Sweden

O. Lindqvist

Department of Nursing, Umeå University,

Umeå, Sweden

A. Peternelj

University Clinic of Respiratory and Allergic diseases,

Golnik, Slovenia

K. Tal

Institute of Social and Preventive Medicine,

University of Bern, Bern, Switzerland

A. van der Heide

Department of Public Health, Erasmus MC Rotterdam, Rotterdam, The Netherlands

\section{S. Eychmüller}

Centre of Palliative Care, University Hospital of Bern, Bern, Switzerland 
the questionnaire, (2) distribution of the Delphi questionnaire and (3) review and synthesis of findings.

Results The first Delphi cycle of 252 participants (health care professionals, volunteers, public) generated 194 different phenomena, perceptions and observations. In the second cycle, these phenomena were checked for their specific ability to diagnose the last hours/days of life. Fifty-eight phenomena achieved more than $80 \%$ expert consensus and were grouped into nine categories. In the third cycle, these 58 phenomena were ranked by a group of palliative care experts (78 professionals, including physicians, nurses, psycho-social-spiritual support; response rate $72 \%$, see Table 1) in terms of clinical relevance to the prediction that a person will die within the next few hours/days. Twenty-one phenomena were determined to have "high relevance" by more than $50 \%$ of the experts. Based on these findings, the changes in the following categories (each consisting of up to three phenomena) were considered highly relevant to clinicians in identifying and predicting a patient's last hours/days of life: "breathing", "general deterioration", "consciousness/cognition", "skin", "intake of fluid, food, others", "emotional state" and "non-observations/expressed opinions/other".

Conclusion Experts from different professional backgrounds identified a set of categories describing a structure within which clinical phenomena can be clinically assessed, in order to more accurately predict whether someone will die within the next days or hours. However, these phenomena need further specification for clinical use.

Keywords Phenomena $\cdot$ Delphi technique $\cdot$ Last hours/days of life

\section{Background}

A minority of deaths in Europe occur suddenly and completely unexpectedly [1]. The majority of patients die from progressive disease or frailty. Achieving the best care of the dying should be recognised as a core clinical proficiency and an integral part of comprehensive cancer management, as fundamental as diagnosis and treatment. Patients in the dying phase should receive the best possible support to meet their individual needs. Technical expertise should be integrated with a humanistic and ethical orientation.

The potential adverse impact of futile treatment on the quality of life of patients with advanced cancer has received broad public and professional attention and is an important consideration in cancer care [2]. This is especially true for imminently dying patients in the very last hours and days of life.

A key area to address is recognition or "diagnosis" that a patient is dying. But clinically assessing the point at which a patient enters the last hours or days of life is a complex challenge. Despite growing interest in predictive factors in cancer over the last decades [3], no valid tool has yet been developed to recognise the dying phase in a cancer disease trajectory. Some clinical signs (e.g. weight loss in the past 3 months, oedema, ascites, jaundice and cognitive status) and symptoms (e.g. pain, dyspnoea, fatigue/tiredness, etc.) have been suggested as good predictors for the last hours and days of a patient's life but are not well described in the literature $[4,5]$. This lack is surprising compared to the frequency of such clinical situations and the intensity of problems and crisis that may accompany the dying phase.

A number of prognostic scoring systems, such as the Palliative Prognostic Score (Pap Score) [6] and Palliative Prognostic Index [7], are designed to accurately predict survival in terminally ill cancer patients. While these can be useful in clinical practice, they are not created to identify the imminent dying phase, i.e. the last hours or days of life.

End-of-life care pathways, such as the Liverpool Care Pathway for the dying patient (LCP), support care for patients and families during the last hours and days of life [8]. The LCP provides a framework for its application but lacks, as do the other tools, rigorous scientific evidence. In order to provide adequate care in the dying phase, and to ensure that patients who are not dying are given appropriate treatment, tools to diagnose dying must be developed for clinical use. The phenomena routinely seen in dying patients should thus be identified and described.

The aim of this study was to describe the most pertinent phenomena in identifying whether a patient is in the last hours or days of life. This study is part of the OPCARE9 project funded by the European Commission's Seventh Framework Programme. OPCARE9 aims to reach consensus, based on current practice and available research evidence, on the optimum care to be delivered in the last hours and days of the lives of cancer patients and to identify gaps in the knowledge base.

\section{Definitions}

There is no widely accepted strict definition of the "dying phase". For the purposes of this study, the dying phase was defined as the last 7 days of life.

"Diagnosing" dying, and the use of terms like "signs and symptoms," reflects the biomedical model $[9,10]$. Therefore, we chose the more comprehensive term "phenomenon" to facilitate inclusion of any information (e.g. from laypersons) that might play an important role in recognising the last hours and days of life of terminally ill patients.

Delphi technique was chosen to generate phenomena associated with approaching death. The Delphi technique is an effective method for collecting and synthesising informed opinions on a highly focused topic and serves to highlight the perspectives of experts who have specialised knowledge in the area of interest [11]. 


\section{Methods}

Expert groups

Two expert groups were established.

The synthesis group was established within the OPCARE9 collaboration and consisted of members of work package $1^{1}$ from Switzerland and country representatives ${ }^{2}$ of Italy, the Netherlands, Sweden, Germany, UK, Argentina, New Zealand and Slovenia (the nine participating countries in OPCARE9). Participants included nurses, physicians and researchers. The group developed the questionnaires and reviewed and synthesised the results.

The palliative care expert group consisted of health care professionals and lay care persons/volunteers from various care settings (Table 1), who were experienced in palliative care and care of those in the last hours and days of life. They were all able to communicate in English and questionnaires were in English. This group was representing a broad spectrum of professional backgrounds, experiences and opinions to encourage diversity in described phenomena [12]. A core group of 36 experts (four from each OPCARE9 country, see "Cycle 2") represented various professions. The core group was invited to participate in each cycle.

\section{Study design}

To collate a set of useful and relevant phenomena helpful for identification of the last 7 days of life, the Delphi process was arranged in three cycles. Each cycle contained (1) development of the questionnaire, (2) distribution of the Delphi questionnaire and (3) review and synthesis of findings. The output of each cycle formed the basis of the subsequent questionnaire (Fig. 1). Questionnaires were distributed in both paper and electronic version. Questionnaires returned after the deadline were not included for analysis.

\section{Cycle 1}

The goal of the first cycle was to collect a broad spectrum of phenomena as possible.

The expert group (see above) was invited to respond to the following request:

Please list a maximum of four phenomena, observations or perceptions which seem important to you while trying to identify that somebody will die within the next hours or days.

\footnotetext{
${ }^{1}$ Five core themes, pertinent to the care of cancer patients in the last days of life, were structured as primary work packages.

${ }^{2}$ Country representatives provided easy access to health care professionals and volunteers in the field of palliative care in each OPCARE9 country.
}

Table 1 Expert groups 1, 2 and 3

Experts \% (n)

Expert group 1
Country

$\begin{array}{lc}\text { Switzerland } & 65(164) \\ \text { New Zealand } & 1.2(3) \\ \text { Argentina } & 6(15) \\ \text { Netherlands } & 2.4(6) \\ \text { Sweden } & 5.5(14) \\ \text { Germany } & 3.6(9) \\ \text { UK } & 3.6(9) \\ \text { Italy } & 0(0) \\ \text { Slovenia } & 12.7(32) \\ \text { Complete } & 100(252) \\ \text { Medical doctor } & 18.6(47) \\ \text { Nurse } & 34.1(86) \\ \text { Psychologist } & 4.4(11) \\ \text { Social worker } & 3.2(8) \\ \text { Spiritual guidance } & 1.6(4) \\ \text { Volunteer } & 6.3(16) \\ \text { Public } & 3.6(9) \\ \text { Other } & 2(5) \\ \text { Occupational therapist } & 0.8(2) \\ \text { Volunteer coordinator } & 0.4(1) \\ \text { unknown } & 25(63) \\ \text { Complete } & 100(252)\end{array}$

Expert group 2

Country

Switzerland

$8.3(3)$

New Zealand

$11.1(4)$

Argentina

$14(5)$

Netherlands

$11.1(4)$

Sweden

11.1 (4)

Germany

$11.1(4)$

UK

11.1 (4)

Italy

11.1 (4)

Slovenia

11.1 (4)

Complete

$100(36)$

Profession

Medical doctor

28 (10)

Nurse

25 (9)

Psychologist

11 (4)

Social worker

11 (4)

Spiritual guidance

3 (1)

Volunteer

17 (6)

Volunteer coordinator

5 (2)

unknown

$0(0)$

Complete

$100(36)$

Expert group 3 Country

$\begin{array}{lc}\text { Switzerland } & 13(10) \\ \text { New Zealand } & 13(10) \\ \text { Argentina } & 6(5) \\ \text { Netherlands } & 13(10) \\ \text { Sweden } & 15(12)\end{array}$


Table 1 (continued)

\begin{tabular}{llc}
\hline & & Experts \% $(n)$ \\
\hline Germany & $8(6)$ \\
UK & $6(5)$ \\
Italy & $9(7)$ \\
Profession & Clovenia & $17(13)$ \\
& Medical doctor & $100(78)$ \\
& Nurse & $44(34)$ \\
& Psychologist & $33(26)$ \\
& Social worker & $9(7)$ \\
& Spiritual guidance & $5(4)$ \\
& Volunteer coordinator & $8(6)$ \\
Complete & $100(1)$ \\
\hline
\end{tabular}

Data collection was halted when each professional group (nurses, physicians, psycho-social-spiritual professionals, e.g. social workers, psychologists, priests, etc.) and volunteers from all collaborating countries were represented (Table 1).
Cycle 2

Based on the results of the previous cycle, Delphi cycle 2 was aimed at phenomena occurring exclusively during the last days and hours of a patient's life. This cycle was designed to assess the importance of each phenomenon in this specific context.

Delphi questionnaire 2 was sent to a subset of the palliative care expert group defined by profession (a total of 36 experts from cycle 1, one per profession for each OPCARE9 country, Table 1). The representativeness of the subset was later checked in cycle 3 by verifying the congruence of Delphi 2 and 3 outputs. The experts were asked the following question:

Do you agree that this phenomenon is important when identifying or recognising the last hours or days of life?

The answer scale included four options: (1) I strongly disagree, (2) I disagree, (3) I agree and (4) I strongly agree. Demographic data were also collected from the expert panel (profession, country).
Fig. 1 Study design of Delphi process

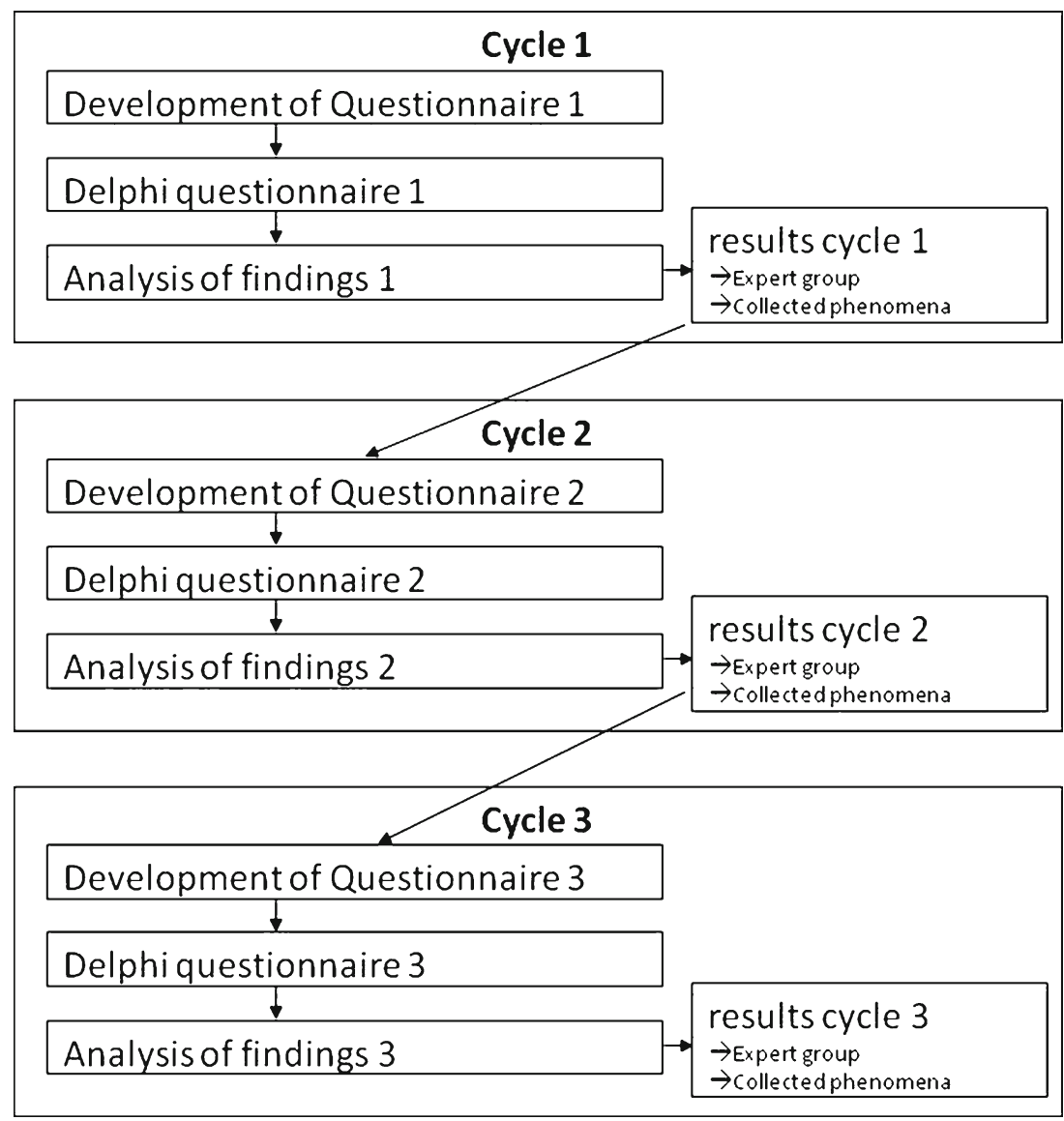




\section{Cycle 3}

In the third cycle, the phenomena identified in cycle 2 were ranked. Delphi questionnaire 3 was sent to the expert group, which included a minimum of 12 experts from each collaborating country, representing all professions (four nurses, four doctors and four psycho-social-spiritual professionals) (Table 1). Volunteers were not included in cycle 3 because their feedback in the cycle 2 questionnaire indicated a belief that medical expertise was mandatory in order to answer the questions.

The question in cycle 3 was:

Please rate the following phenomena in terms of their clinical relevance to predict that someone will die within the next few hours/days.

Phenomena grouped into categories had to be rated on the following scale: (1) no relevance, (2) low relevance, (3) medium relevance, (4) high relevance and (5) highest relevance. Respondents also had the options of "no answer" and "comments". An "add-in-option for phenomena missing" in the respective category was also offered.

\section{Analysis and statistical methods}

Cycle 1 Content analysis according to Mayring ${ }^{3}$ [13] was used to analyse the collected phenomena (output 1) [14]. All questionnaires were reviewed independently by two researchers. Duplicate phenomena were excluded. Disagreements were discussed until consensus on inclusion/exclusion was achieved. The definitive decision on inclusion of phenomena was made by the synthesis group.

Cycle 2 Answers were dichotomized into disagreement $=1$, strong disagreement, and 2, disagreement, and into agree$m e n t=3$, agreement, and 4, strong agreement. As a basis for the development of the cycle 3 questionnaire, output 2 included phenomena that received more than $80 \%$ expert consensus on agreement. The synthesis group qualitatively analysed all phenomena and created categories. Phenomena were coded independently by three researchers and categorised with the synthesis group until congruence was achieved.

Cycle 3 For analysis and synthesis of findings, answers were dichotomized into high relevance $=4$, high, and 5, highest relevance, and into low relevance $=1$, no relevance; 2 , low relevance; and 3, medium relevance. Cycle 3 incorporated phenomena and respective categories that achieved more than $50 \%$ expert consensus on "high relevance" in

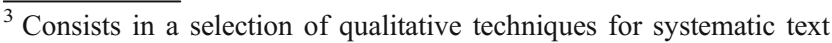
analysis
}

predicting that someone would die within the next few hours/days. To avoid the risk of losing potential valuable phenomena, a lower percentage of expert consensus $(50 \%)$ was chosen.In all three cycles, demographic data (profession, country, setting, years of experience in palliative care) were collected, and descriptive analysis of data (frequencies, percentages of expert panel and collected phenomena and crosstabs inclusive of Chi-square test) was performed using statistical software SPSS.

\section{Results}

\section{Output cycle 1}

We evaluated 252 questionnaires $(65 \%$ health care professionals, $6 \%$ volunteers, $4 \%$ public and $25 \%$ missing/ unknown profession) from eight countries, with a response rate of $100 \%$ (see Table 1 ).

This first expert questionnaire generated 194 phenomena, perceptions and observations that seemed to be important for "diagnosing dying". This cycle invoked a very broad spectrum of phenomena, with different levels of abstraction. Phenomena at a lower abstraction level were more specific, such as "difficulty swallowing", "noisy breathing", "changed breathing pattern", "bluish skin" or "cold extremity", whereas phenomena with higher abstraction level were less specific, such as "deterioration", "disconnection" or "passivity". Some phenomena required further clarification, e.g. "intuition of professionals, gut feeling", "death rattle", "is afraid", "fatigue" or "irreversible deterioration of consciousness".

The synthesis group stated that a relatively high number of phenomena were not uniquely related to the last hours/ days of life but might indicate a much earlier phase in the process of decline. Examples included "paleness", "introverted" or "passivity".

Output cycle 2

Thirty-six questionnaires were sent back from the subset of the palliative care expert group $(n=36 ; 83 \%$ health care professionals, $17 \%$ volunteers', representing all nine OPCARE9 countries, see Table 1). A response rate of $100 \%$ was obtained.

Fifty-eight phenomena specifically related to the last hours/days of life received more than $80 \%$ expert consensus on agreement (Table 2) and were subsequently included for cycle 3. Nine categories were created: "breathing", "communication", "consciousness/cognition", "emotional state", "general deterioration", "intake of fluid, food other", "mobility", "non-observations, expressed opinions/other" and "skin". 
Table 2 Included/ excluded phenomena of Delphi cycles 2 and 3

\begin{tabular}{|c|c|c|c|c|}
\hline \multirow[b]{2}{*}{ Included phenomenon } & \multicolumn{2}{|l|}{ Delphi 2} & \multicolumn{2}{|l|}{ Delphi 3} \\
\hline & Valid answers & Agreement $(\geq 80 \%)$ & Valid answers & High relevance $(\geq 50 \%)$ \\
\hline & $N$ & $N(\%)$ & $N$ & $N(\%)$ \\
\hline Death rattles & 35 & $35(100.0)$ & 78 & $64(82.1)$ \\
\hline Changed breathing rhythm & 35 & $34(97.1)$ & 78 & $52(66.7)$ \\
\hline Changes in breathing & 34 & $33(97.1)$ & 78 & $39(50)$ \\
\hline Consciousness level deteriorating and slowing & 35 & $34(97.1)$ & 69 & $42(53.8)$ \\
\hline Irregular breathing & 33 & $32(97.0)$ & 78 & Excl. \\
\hline Cyanosis & 31 & $30(96.8)$ & 68 & Excl. \\
\hline Changes in breathing patterns & 34 & $32(94.1)$ & 78 & $50(64.1)$ \\
\hline Troubles breathing & 33 & $31(93.9)$ & 78 & Excl. \\
\hline Irreversible deterioration of consciousness & 35 & $32(91.4)$ & 69 & $49(62.8)$ \\
\hline Marble-like skin & 35 & $32(91.4)$ & 69 & $41(52.6)$ \\
\hline Physical deterioration & 35 & $32(91.4)$ & 69 & $26(33.3)$ \\
\hline Rapid degradation of general condition & 35 & $32(91.4)$ & 69 & $47(60.3)$ \\
\hline Comatose & 35 & $32(91.4)$ & 69 & $48(61.5)$ \\
\hline Intuition of professionals, gut feeling & 34 & $31(91.2)$ & 69 & $45(57.7)$ \\
\hline Organ failure & 34 & $31(91.2)$ & 69 & $51(65.4)$ \\
\hline Increased bronchial secretion & 32 & $29(90.9)$ & 78 & Excl. \\
\hline Extreme weakness & 36 & $32(88.9)$ & 69 & Excl. \\
\hline Cannot drink & 35 & $31(88.6)$ & 69 & $41(52.6)$ \\
\hline Cannot eat & 35 & $31(88.6)$ & 69 & Excl. \\
\hline Cold extremity & 35 & $31(88.6)$ & 69 & $37(53.6)$ \\
\hline No fluid or food intake & 35 & $31(88.6)$ & 69 & $48(69.6)$ \\
\hline Noisy breathing & 35 & $31(88.6)$ & 78 & Excl. \\
\hline Reduced cognition and attention & 35 & $31(88.6)$ & 69 & Excl. \\
\hline Skin colour changes & 35 & $31(88.6)$ & 69 & Excl. \\
\hline Impaired cognition & 36 & $32(88.3)$ & 69 & Excl. \\
\hline Bluish skin & 34 & $30(88.2)$ & 69 & Excl. \\
\hline Semi-comatose & 34 & $30(88.2)$ & 69 & $36(52.2)$ \\
\hline Bed-ridden & 34 & $30(88.2)$ & 69 & Excl. \\
\hline Burbling sounds & 32 & $28(87.5)$ & 78 & Excl. \\
\hline Somnolent & 32 & $28(87.5)$ & 69 & Excl. \\
\hline Agitation & 36 & $31(86.1)$ & 69 & Excl. \\
\hline Communicates less than before & 36 & $31(86.1)$ & 69 & Excl. \\
\hline Difficulty to talk & 36 & $31(86.1)$ & 69 & Excl. \\
\hline Diminished cognition & 35 & $30(85.7)$ & 69 & Excl. \\
\hline Discoloration of skin & 35 & $30(85.7)$ & 69 & Excl. \\
\hline Reduced urine production & 34 & $29(85.3)$ & 69 & Excl. \\
\hline Peripheral shut-down & 27 & $23(85.2)$ & 69 & $40(58)$ \\
\hline Cheeks hollow and sunken & 33 & $28(84.8)$ & 69 & Excl. \\
\hline Mottled skin & 33 & $28(84.8)$ & 69 & Excl. \\
\hline Pale and frail appearance & 31 & $26(83.9)$ & 69 & Excl. \\
\hline Changed facial expression & 35 & $29(82.9)$ & 69 & Excl. \\
\hline Deterioration & 35 & $29(82.9)$ & 69 & Excl. \\
\hline Not able to get up & 35 & $29(82.9)$ & 69 & Excl. \\
\hline Psychic/ mental condition is deteriorating & 35 & $29(82.9)$ & 69 & Excl. \\
\hline Restlessness & 34 & $28(82.4)$ & 69 & $35(50.7)$ \\
\hline Inability to stand/ walk & 34 & $28(82.4)$ & 69 & Excl. \\
\hline
\end{tabular}


Table 2 (continued)

\begin{tabular}{|c|c|c|c|c|}
\hline \multirow[b]{2}{*}{ Included phenomenon } & \multicolumn{2}{|l|}{ Delphi 2} & \multicolumn{2}{|l|}{ Delphi 3} \\
\hline & Valid answers & Agreement $(\geq 80 \%)$ & Valid answers & High relevance $(\geq 50 \%)$ \\
\hline Intuition of family/ relatives & 34 & $28(82.4)$ & 69 & Excl. \\
\hline Refusal of fluid or food & 33 & $27(82.4)$ & 69 & Excl. \\
\hline Cannot take medicine & 33 & $27(81.8)$ & 69 & Excl. \\
\hline Changed attention & 33 & $27(81.8)$ & 69 & Excl. \\
\hline Irreversible status & 32 & $26(81.8)$ & 69 & $39(56.5)$ \\
\hline Pale around nose and mouth & 35 & $28(81.3)$ & 69 & $41(59.4)$ \\
\hline Apathy towards environment & 35 & $28(80.0)$ & 69 & Excl. \\
\hline Bedbound & 35 & $28(80.0)$ & 69 & Excl. \\
\hline Facial colour changed & 35 & $28(80.0)$ & 68 & Excl. \\
\hline Loss of body functions & 35 & $28(80.0)$ & 69 & Excl. \\
\hline Reduced fluid or food intake & 35 & $28(80.0)$ & 69 & Excl. \\
\hline Swallowing impossible & 35 & $28(80.0)$ & 69 & $38(55.1)$ \\
\hline
\end{tabular}

The most frequent reason for not answering was lack of semantic clarity or misunderstanding the term describing the respective phenomenon. Missing answers in each of the 194 rated phenomena ranged from 0 to $25 \%$ (count 0 to 9 , see Table 2). The phenomenon "peripheral shut-down" was unanswered by nine experts ( $25 \%)$. Other unanswered phenomena included "cyanosis", "pail and frail appearance", "burbling sounds", "somnolent" and "irreversible status".

Output cycle 3

In the third cycle ("ranking"), 78 palliative care experts (physicians, nurses, psycho-social-spiritual professionals; see Table 1), from nine countries, were invited to participate. Response rate was $72 \%$. Twenty-one phenomena from seven categories received more than $50 \%$ expert consensus on their high relevance to predictions that someone would die within the next few hours/days (Table 2). The seven categories were: "breathing", "consciousness/cognition", "emotional state", "general deterioration", "intake of fluid, food other", "non-observations/expressed opinions/other" and "skin". The categories "mobility" and "communication" were discarded after this process. Missing answers ranged from 0 to $12.8 \%$ (count 0 to 10 ).

Palliative care experts also noted in free text that some phenomena were missing in the questionnaire, mainly in the

Table 3 Cross tabulation of profession relevance rating of ten phenomena of approaching death, $p$ value

\begin{tabular}{|c|c|c|c|c|c|c|c|c|c|c|c|c|c|}
\hline \multirow[b]{2}{*}{ Phenomenon } & \multicolumn{12}{|c|}{ Profession } & \multirow{2}{*}{$\begin{array}{l}p \\
\text { value }\end{array}$} \\
\hline & MD & $\begin{array}{l}\text { LR } \\
\%\end{array}$ & $\begin{array}{l}\mathrm{HR} \\
\%\end{array}$ & $\begin{array}{l}\mathrm{N} / \\
\mathrm{A}\end{array}$ & $\mathrm{RN}$ & $\begin{array}{l}\text { LR } \\
\%\end{array}$ & $\begin{array}{l}\mathrm{HR} \\
\%\end{array}$ & N/A & PSSP & $\begin{array}{l}\text { LR } \\
\%\end{array}$ & $\begin{array}{l}\mathrm{HR} \\
\%\end{array}$ & N/A & \\
\hline Death rattle & & 14.7 & 85.3 & - & & 11.5 & 84.6 & 3.8 & & 5.6 & 72.2 & 22.2 & 0.162 \\
\hline Organ failure & & 23.5 & 73.5 & 2.9 & & 11.5 & 84.6 & 3.8 & & 16.7 & 66.7 & 16.7 & 0.235 \\
\hline $\begin{array}{l}\text { Irreversible deterioration of } \\
\text { consciousness }\end{array}$ & & 29.4 & 70.6 & - & & 19.2 & 69.2 & 11.5 & & 16.7 & 77.8 & 5.6 & 0.284 \\
\hline $\begin{array}{l}\text { Rapid degradation of general } \\
\text { condition }\end{array}$ & & 29.4 & 67.6 & 2.9 & & 23.1 & 69.2 & 7.7 & & 16.7 & 77.8 & 5.6 & 0.800 \\
\hline Comatose & & 20.6 & 76.5 & 2.9 & & 34.6 & 61.5 & 3.8 & & 16.7 & 66.7 & 16.7 & 0.191 \\
\hline No fluid or food intake & & 23.5 & 73.5 & 2.9 & & 34.6 & 57.7 & 7.7 & & 22.2 & 72.2 & 5.6 & 0.712 \\
\hline Changed breathing rhythm & & 23.5 & 73.5 & 2.9 & & 34.6 & 61.5 & 3.8 & & 33.3 & 61.1 & 5.6 & 0.850 \\
\hline Changes in breathing patterns & & 26.5 & 67.6 & 5.9 & & 42.3 & 57.7 & - & & 27.8 & 66.7 & 5.6 & 0.551 \\
\hline $\begin{array}{l}\text { Intuition of professionals, gut } \\
\text { feeling }\end{array}$ & & 38.2 & 61.8 & - & & 26.9 & 69.2 & 3.8 & & 33.3 & 61.1 & 5.6 & 0.664 \\
\hline $\begin{array}{l}\text { Conscious level deteriorating and } \\
\text { slowing }\end{array}$ & & 26.5 & 67.6 & 5.9 & & 50.0 & 46.2 & 3.8 & & 27.8 & 66.7 & 5.6 & 0.394 \\
\hline
\end{tabular}

$M D$ medical doctor, $R N$ registered nurse, $P S S P$ psycho-social-spiritual professional, $L R$ low relevance, $H R$ high relevance, $N / A$ no answer 
category breathing. Apnoea, superficial breathing and Cheyne-Stokes respiration were mentioned and rated as highly relevant.

Cross tabulation of professional groups (medical doctors, registered nurses and psycho-social-spiritual professionals) and relevance rating of phenomena of approaching death produced different ratings between professions. But results of Chi-square tests showed that there was no significant association between profession and the tested phenomena (Table 3). Accordingly professional groups did not rate significantly differently.

\section{Discussion}

This study, the first of its type, gives evidence to clinically relevant phenomena that can identify and predict the last hours and days of life.

Due to the lack of evidence in the literature (cite review article if accepted in the same journal), Delphi technique was chosen to compile a set of useful phenomena of approaching death. Delphi technique is frequently used to generate rather than to test hypotheses, to map out a field rather than to test relationships within it [15].

A broad Delphi approach was chosen to guarantee heterogeneity and diversity of data: we used open questions in questionnaire 1, selected palliative care professionals from a variety of care backgrounds and countries, and included lay care persons and volunteers. Professional bias within the study is a risk. The high percentage of participating physicians and nurses may have generated an overrepresentative list of physical and psychological phenomena (e.g. categories such as breathing, emotional state; see Table 3). However, the identified phenomena generally lack specificity for direct clinical use in various diseases or diagnosis. For example "change in breathing" has not been specified in more detail as, for example, in "orthopnea due to muscle weakness" or "tachypnea, $>25$ per min".

In addition to these phenomena, palliative care experts rated intuition/gut feeling as clinically relevant. This is not surprising because another prognostic tool, the PaP Score, has weighted clinical estimation of survival as its most powerful factor [18]. Intuition should be considered part of the theoretical concept. The emphasis placed on it by palliative care experts is an indication that it is important in practice. If so, theory and empiricism are mutually reinforcing and might together facilitate discussion about the concept of intuition and the framing of new hypotheses [16].

This set of phenomena indicating approaching death in terminally ill patients might be useful as a starting point for recognising the onset of dying and adding to the discussion of appropriate care in the patient's final hours and days of life.

\section{Limitations}

It should be recognised that our data might not be generalisable due to the frequency of occurrence in real clinical settings. Our intention was to investigate a variety of phenomena, and correlations in terms of settings, professions and diseases should be drawn cautiously. Because expert opinions rather than clinical observation were used, connection to daily practice is questionable. Some descriptions were not very detailed, and we did not ask for cutoff points.

In the future, it will be useful to investigate international expert opinion regarding the most important phenomena related to the last days of life.

There remain two important issues related to diagnosing dying. First, there exists no common definition of the dying phase that captures processes and phenomena. It is possible that this last part of life will continue to be characterised by a mix of myths and observable phenomena, and a more detailed "diagnosing" would not be possible even with a more sophisticated approach. Second, it has not yet been demonstrated that a more accurate diagnosis of the dying phase will provide concrete benefits. But there is increasing evidence for the importance of improving communication [17]. Clear and compassionate communication focused on the individual needs of patients and families can help to deliver high quality care at the end of life.

Our results may facilitate future research into the diagnosis of dying. We believe that the processual character of many phenomena ("changes in....") requires more attention. There is also a need for longitudinal/repetitive assessment of signs and symptoms in the dying phase.

A prospective, observational and longitudinal multicentre study should be carried out to test sensitivity and specificity of the compiled phenomena and categories, respectively. Results of future research will inform and be included in clinical tools like the Liverpool Care Pathway [18].

Acknowledgments OPCARE9 is funded by the European Commission's Seventh Framework Programme (contract number: HEALTHF2-2008-202112) with the aim of improving care in the last days of life by systematically identifying existing knowledge as well as knowledge gaps. The project aims to do this collaboratively across Europe and beyond to integrate knowledge from a range of health care environments and cultures and to avoid duplication of resource and effort. Project outputs include the dissemination of key findings and recommendations for further research and development for care in the last days of life. Further information on OPCARE9, its members, work packages, outputs and contact details, can be found online at www.mcpcil.org.uk/mcpcil/research-development/opcare9.

We would like to thank our OPCARE9 colleagues John Ellershaw, Carl Johan Furst, Maren Galushko, Carina Lundh Hagelin, Stephen Mason, Ovidiu Popa Velea, Natasja Raijmakers, Vanessa Romotzky, Ruthmarijke Smeding, Raymond Voltz and Lia van Zuylen for their valuable collaboration. We would also like to thank Kali Tal for her editorial work. 
Conflict of interest The authors declare that there is no conflict of interest and the study was conducted in accordance with the ethical standards. All authors have substantially contributed to data collection, data analysis and interpretation, drafting and revising the article and finally approved to the publication of the submitted version.

The first author has full control of all primary data and agrees to allow the journal to review the data if requested.

\section{References}

1. Scott K (2010) Incidence of sudden, unexpected death in a specialist palliative care inpatient setting. Palliat Med 24(4):449-450

2. Behl D, Jatoi A (2010) What do oncologists say about chemotherapy at the very end of life? Results from a semiqualitative survey. J Palliat Med 13(7):831-835

3. Lau F, Cloutier-Fisher D, Kuziemsky C, Black F, Downing M, Borycki E et al (2007) A systematic review of prognostic tools for estimating survival time in palliative care. J Palliat Care 23(2):93-112

4. Chiang JK, Cheng YH, Koo M, Kao YH, Chen CY (2010) A computer-assisted model for predicting probability of dying within 7 days of hospice admission in patients with terminal cancer. Jpn J Clin Oncol 40(5):449-455

5. Toscani P, Brunelli C, Miccinesi G, Costantini M, Gallucci M, Tamburini $M$ et al (2005) Predicting survival in terminal cancer patients: clinical observation or quality-of-life evaluation? Palliat Med 19(3):220-227

6. Maltoni M, Caraceni A, Brunelli C, Broeckaert B, Christakis N, Eychmüller $S$ et al (2005) Prognostic factors in advanced cancer patients: evidence-based clinical recommendations - a study by steering committee of the European Association for Palliative Care. J Oncol 23(25):6240-6248

7. Morita T, Tsunoda J, Inoue S, Chihara S (1999) The Palliative Prognostic Index: a scoring system for survival prediction of terminally ill cancer patients. Support Care Cancer 7(3):128-133

8. Ellershaw JE, Wilkinson S (2010) Care of the dying: a pathway to excellence, 2nd edn. Oxford University Press, Oxford

9. Higginson Irene J, Addington-Hall Julia M (2005) The epidemiology of death and symptoms. In: Doyle D, Hanks G, Cherny N, Calman K (eds) Oxford textbook of palliative medicine, 3rd edn. Oxford University Press, Oxford, pp 14-24

10. King LS (1984) Medical thinking: a historical preface. Princeton University Press, Princeton

11. Biondi Patricia D, Nekolaichuk CL, Stiles C, Fainsinger R, Hagen NA (2008) Applying the Delphi process to palliative care tool development: lessons learned. Support Care Cancer 16:935-942

12. Franks PJ, Salisbury C, Bosanquet N, Wilkinson EK, Kite S, Naysmith A et al (2000) The level of need for palliative care: a systematic review of literature. Palliative Med 14(2):93-104

13. Mayring P (2000) Qualitative content analysis. Qual Soc Res 1(2)

14. Treibel A (2000) Einfuihrung in soziologische Theorien der Gegenwart, 5th edn. Leske + Budrich, Opladen

15. Häder M (2002) Delphi-Befragungen, 1st edn. Westdeutscher, Wiesbaden

16. Yun AJ (2008) The hegemony of empiricism: the opportunity for theoretical science in medicine. Med Hypotheses 70(3):478-481

17. Steinhauser KE, Christakis NA, Clipp EC, McNeilly M, McIntyre L, Tulsky JA (2000) Factors considered important at the end of life by patients, family, physicians, and other care providers. JAMA 284(19):2476-2482

18. Ellershaw J (2007) Care of the dying: what a difference an LCP makes! Palliat Med 21(5):365-368 